\title{
A Symptomatic Case of Adenomatous Ductal Proliferation/ Hyperplasia with a Large Cystic Lesion
}

\author{
Nobuhiko Seki ${ }^{a, e} \quad$ Norikazu Yamazaki ${ }^{b}$ Tatsuru Ikeda ${ }^{c} \quad$ Hiroshi Hadara $^{d}$ \\ Tetsuo Himi ${ }^{\mathrm{e}}$ \\ ${ }^{\mathrm{a}}$ Teine Clover Otolaryngology Clinic, Sapporo, Japan; ${ }^{\mathrm{b}}$ Department of Otolaryngology, \\ Hakodate Goryokaku Hospital, Hakodate, Japan; ' $P$ athology Center, Hakodate Goryokaku \\ Hospital, Hakodate, Japan; ${ }^{d}$ Department of Diagnostic Pathology, Seichokai Fuchu \\ Hospital, Izumi, Japan; ${ }^{\mathrm{e}}$ Department of Otolaryngology, Sapporo Medical University \\ School of Medicine, Sapporo, Japan
}

\section{Keywords}

Adenomatous ductal proliferation/hyperplasia · Neoplasm · Salivary gland disease

\section{Abstract}

Adenomatous ductal proliferation/hyperplasia $(\mathrm{ADP} / \mathrm{H})$ of the salivary gland, a rare asymptomatic nonneoplastic lesion that histopathologically resembles basal cell adenoma, is typically incidentally identified in resected specimens of other salivary diseases such as tumors and chronic sialadenitis. A 70-year-old male was referred to our hospital with a 9-month history of continuous swelling in the left parotid region. A physical examination revealed a soft mass in the left parotid gland, which was identified as a cystic mass by computed tomography. A parotid tumor with cystic components was suspected, and partial parotidectomy was performed under general anesthesia. The histopathological findings were consistent with the diagnosis of ADP/H of the salivary gland. This case report emphasizes the necessity for a proper diagnosis of ADP/H of the salivary gland. Further large case series are required for a modification of the definition of ADP/H for its correct diagnosis. 
 Oncology}

\section{Introduction}

Adenomatous ductal proliferation/hyperplasia (ADP/H) of the salivary gland is a nonneoplastic lesion initially described by Yu and Donath [1] in 2001 which has not been widely documented. The histopathological findings in ADP/H closely resemble those in basal cell adenoma; however, it frequently lacks a capsular structure, thereby mimicking basal cell adenocarcinoma. The lesions are usually small, asymptomatic masses that are incidentally identified in resected specimens of other salivary gland disorders such as neoplasms and chronic inflammation.

Here, we report the case of a symptomatic patient with ADP/H that presented with a cystic mass measuring $3 \mathrm{~cm}$ in diameter in the left parotid gland, which, to our knowledge, is the largest ADP/H lesion documented in the English-language literature. This case illustrates the importance of a correct diagnosis of $\mathrm{ADP} / \mathrm{H}$ lesions by pathologists and otolaryngologists.

\section{Case Report}

A 70-year-old Japanese male was referred to a regional hospital with a 9-month history of continuous swelling in the left parotid region. A physical examination revealed a soft mass located in the left parotid gland. A computed tomography scan showed an irregularly shaped, well-circumscribed mass with a low-density area in the left parotid gland (Fig. 1a). A parotid tumor was suspected, and partial parotidectomy was performed under general anesthesia. A $3 \times 2 \mathrm{~cm}$ soft mass was located deep in the lobe of the parotid gland, immediately under the buccal branch of the facial nerve (Fig. 1b). No facial nerve weakness was observed postoperatively.

A postoperative histopathological analysis of the specimen demonstrated closely packed ductal structures in close contact with a unilocular cystic structure; both components exhibited a double-layered arrangement (Fig. 2a, b). Both the ductal and the cystic structures comprised luminal cells with eosinophilic cytoplasm and basaloid cells with scant cytoplasm arranged in the outer layer. While secondary fibrosis was found in the stroma, a definitive fibrous capsule between the lesion and the surrounding fatty tissue or the parotid parenchyma was not observed (Fig. 2c-e). These findings were reminiscent of basal cell adenoma or basal cell adenocarcinoma. In some areas, the presence of diastase-resistant PAS-positive inclusions indicated the luminal surfaces of the ducts (Fig. 2f); these distinctive granular inclusions were assumed to indicate residual zymogen granules originating from serous acinar cells. Furthermore, a transitional appearance was directly observed between the preexisting acinar units and the small ducts. Immunostaining for S100 protein showed positive staining of the inner luminal layer of the double-layered ducts (Fig. $2 \mathrm{~g}$ ). A focal positive immunoreactivity for S100 protein was observed in the stromal fibroblast-like cells (Fig. 2h). Smooth muscle actin and p63 highlighted the outer myoepithelial layer of the doublelayered ducts (Fig. 2i, j). Taken together, these findings suggested a close relationship between the preexisting acinar units and the resected lesion, which was histopathologically consistent with the diagnosis of $\mathrm{ADP} / \mathrm{H}$. Following resection, no evidence of recurrence was observed during the 8-year follow-up period. 
 Oncology}

\section{Discussion}

ADP/H was initially described as an adenomatous ductal proliferation by Yu and Donath in 2001 [1]. However, Di Palma [2] and Chetty [3] reported similar lesions that were thought to arise from a hyperplastic change in intercalated ducts and suggested the presence of a close relationship between these lesions and epithelial-myoepithelial carcinoma. Therefore, we propose $\mathrm{ADP} / \mathrm{H}$ as a unifying definition that encompasses previous terms used for such lesions in salivary glands.

$\mathrm{ADP} / \mathrm{H}$ is a non-neoplastic mass, usually a small lesion involving a few lobules, in salivary glands; therefore, patients are typically asymptomatic. Most lesions are incidentally detected in resected specimens of other salivary gland diseases, such as neoplasms and chronic inflammation. The current case was unique, since our symptomatic patient, who presented with swelling in the parotid area, had the largest ADP/H lesion reported in the English-language literature: it was $3 \mathrm{~cm}$ in diameter and contained a cystic structure.

The pathological findings and developmental process of ADP/H were extensively described by $\mathrm{Yu}$ and Donath [1]. The pathogenesis of ADP/H is assumed to involve atrophy of salivary glandular tissue, which usually occurs due to salivary tissue destruction and secretory dysfunction associated with starvation, radiation therapy, chronic sialadenitis, and sialolithiasis. Salivary gland atrophy can also occur after ductal obstruction and stagnation of secretions due to long-term pressure exerted by a tumor or chronic inflammation [1]. Atrophic changes in acinar cells include the loss of zymogen granules and morphological transformation mimicking the proliferation of intercalated ducts, which represents acinar cell dedifferentiation [4]. Atrophy or dedifferentiation of acinar cells is followed by the regenerative proliferation of small ducts and nests that include basaloid cells resembling those of basal cell adenoma, which results in the formation of nodular foci with an adenomatous arrangement (Fig. 3).

Since the initial case series of 13 patients reported by Yu and Donath in 2001 [1], no new cases of ADP/H have been published. However, several similar cases with intercalated duct lesions have been reported [5-7]. Non-neoplastic lesions including ADP/H and intercalated duct lesions were not included in the World Health Organization (WHO) histological classification of salivary gland tumors published in 2005, and ADP/H is a disorder not widely known to clinicians and pathologists. Furthermore, hyperplastic lesions of the salivary gland may clinically be misdiagnosed as neoplastic tumors, as experienced in a case of oncocytosis (i.e., multifocal adenomatous oncocytic hyperplasia) reported by Kinoshita et al. [8]. The recognition and inclusion of $\mathrm{ADP} / \mathrm{H}$ in the differential diagnosis of salivary gland disorders by otolaryngologists might be hindered by its characterization thus far as an asymptomatic and non-neoplastic disease. However, our patient presented with swelling and a lesion $3 \mathrm{~cm}$ in diameter. Furthermore, the pathological findings of scattered ducts and nests that include basaloid cells within the fibrous stroma resembled adenocarcinomatous invasion, which could lead to misdiagnosis and incorrect therapy. Thus, this case illustrates the critical importance of a proper diagnosis of ADP/H of the salivary gland by both clinicians and pathologists.

Intercalated duct hyperplasia of the salivary gland was described in the new edition of the WHO classification published in 2017. As stated before, the pathogenesis of this lesion is thought to involve atrophy of salivary glandular tissue, which includes loss of zymogen granules, followed by the regenerative proliferation of small ducts and nests, and it is not the result of hyperplastic changes of the preexisting intercalated ducts. Regarding this point, intercalated duct hyperplasia is not always the proper designation, and this is the reason 


\section{Case Reports in Oncology}

\begin{tabular}{|c|c|}
\hline DOI: $10.1159 / 000478997$ & $\begin{array}{l}\text { ( } 2017 \text { The Author(s). Published by S. Karger AG, Basel } \\
\text { www.karger.com/cro }\end{array}$ \\
\hline
\end{tabular}

Seki et al.: A Symptomatic Case of Adenomatous Ductal Proliferation/Hyperplasia with Large Cystic Lesion

why we prefer the term $\mathrm{ADP} / \mathrm{H}$. Therefore, large case series will be necessary for a modification of the definition of ADP/H.

\section{Statement of Ethics}

The patient signed a statement which authorizes the use of the personal and/or medical information in the publication of this case report.

\section{Disclosure Statement}

The authors have no conflicts of interest to disclose.

\section{References}

1 Yu GY, Donath K: Adenomatous ductal proliferation of the salivary gland. Oral Surg Oral Med Oral Pathol Oral Radiol Endod 2001;91:215-221.

-2 Di Palma S: Epithelial-myoepithelial carcinoma with co-existing multifocal intercalated duct hyperplasia of the parotid gland. Histopathology 1994;25:494-496.

3 Chetty R: Intercalated duct hyperplasia: possible relationship to epithelial-myoepithelial carcinoma and hybrid tumours of salivary gland. Histopathology 2000;37:260-263.

4 Bockman DE: Cells of origin of pancreatic cancer: experimental animal tumors related to human pancreas. Cancer 1981;47(suppl):1528-1534.

-5 Weinreb I, Seethala RR, Hunt JL, Chetty R, Dardick I, Perez-Ordoñez B: Intercalated duct lesions of salivary gland: a morphologic spectrum from hyperplasia to adenoma. Am J Surg Pathol 2009;33:13221329.

-6 Naunheim MR, Lin HW, Faquin WC, Lin DT: Intercalated duct lesion of the parotid. Head Neck Pathol 2012;6:373-376.

7 Montalli VA, Martinez E, Tincani A, Martins A, Abreu Mdo C, Neves C, Costa AF, Araújo VC, Altemani A: Tubular variant of basal cell adenoma shares immunophenotypical features with normal intercalated ducts and is closely related to intercalated duct lesions of salivary gland. Histopathology 2014;64:880889.

8 Kinoshita Y, Harada H, Kobayashi TK, Yoshizawa K, Yuri T, Takasu K, Tsubura A, Shikata N: Multifocal adenomatous oncocytic hyperplasia of the parotid gland. Case Rep Oncol 2014;7:819-824. 


\section{Case Reports in Oncology}
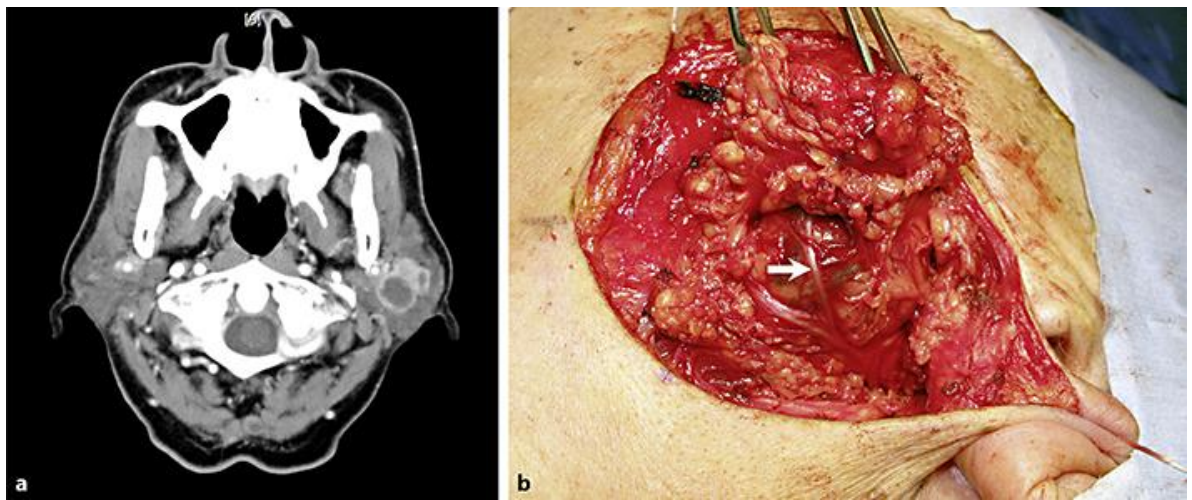

Fig. 1. a Enhanced cervical computed tomography scan showing an irregularly shaped, well-circumscribed mass $3 \times 2 \mathrm{~cm}$ in size, with a low-density area in the left parotid gland. $\mathbf{b}$ A soft mass located under the buccal branch of the facial nerve. Arrow: buccal branch. 


\section{Case Reports in Oncology}

\begin{tabular}{l|l}
\hline Case Rep Oncol 2017;10:676-682 \\
\hline DOI: 10.1159/000478997 & $\begin{array}{l}\text { C 2 2017 The Author(s). Published by S. Karger AG, Basel } \\
\text { www.karger.com/cro }\end{array}$ \\
\hline
\end{tabular}

Seki et al:: A Symptomatic Case of Adenomatous Ductal Proliferation/Hyperplasia with a Large Cystic Lesion
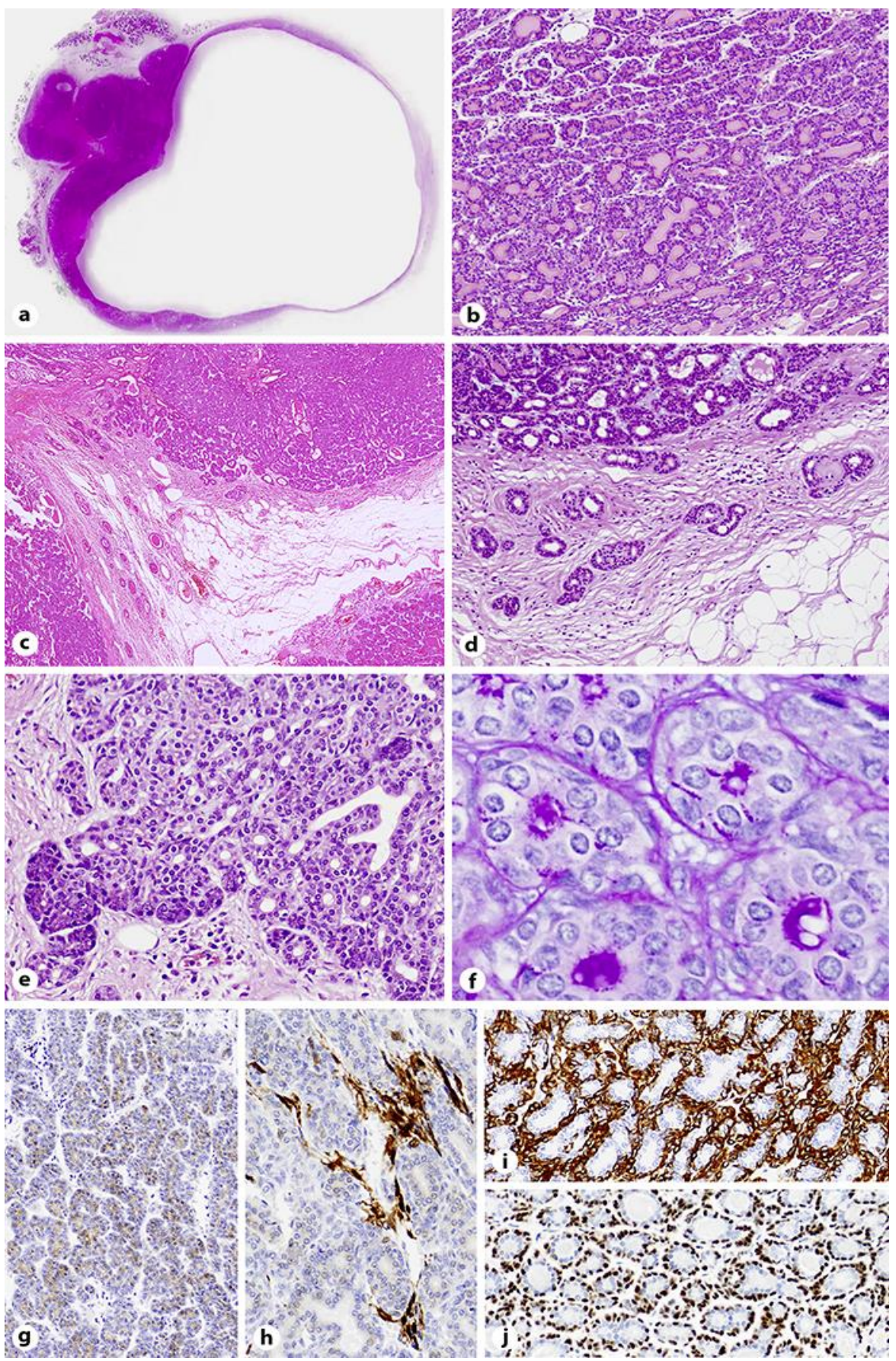

Fig. 2. Photomicrographs of the resected specimen. a, b Basaloid epithelial cells form a unilocular cystic structure and variably sized foci in the periphery of the cyst. c, d Basaloid cells are also observed in the stroma. e Prominent ductal proliferation with admixed acinar cell complexes. $f$ PAS-positive zymogen-like granules are observed in the apical cytoplasmic part of the luminal cells. g Immunostaining for S100 protein shows positive staining of the inner luminal layer of the double-layered ducts. $\mathbf{h}$ A focal positive immunoreactivity for S100 protein is observed in the stromal fibroblast-like cells. $\mathbf{i}, \mathbf{j}$ Smooth muscle actin and p63 highlight the outer myoepithelial layer of the double-layered ducts. 


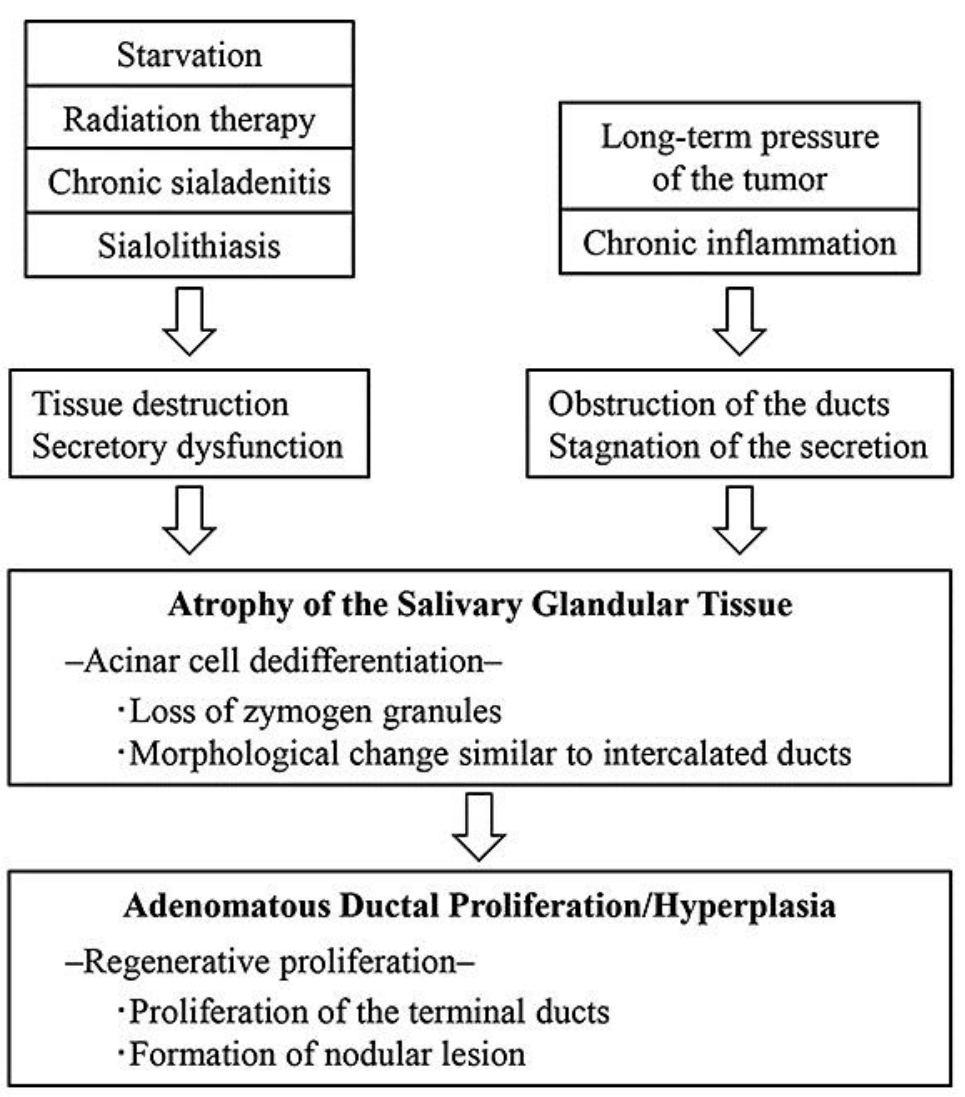

Fig. 3. Pathogenesis of adenomatous ductal proliferation/hyperplasia. 